\title{
DEVELOPMENT OF ATMOSPHERIC PRESSURE PLASMA JET IN AIR
}

\author{
${ }^{1,2}$ R. B. Tyata*, ${ }^{1}$ D. P. Subedi, ${ }^{1}$ A. Shrestha, ${ }^{1}$ D. Baral \\ ${ }^{1}$ Department of Natural Science, Kathmandu University, Dhulikhel, Nepal \\ ${ }^{2}$ Department of Electrical, Khwopa College of Engineering, Libali-2, Bhaktapur, Nepal \\ *Corresponding address: rbtyata@yahoo.com \\ Received 17 October, 2011; Revised 29 December, 2011
}

\begin{abstract}
In this paper, an atmospheric pressure plasma jet (APPJ) in air that is expected to be useful for polymer surface modification has been reported. The plasma jet was produced by applying $(10-30) \mathrm{kHz},(0-20) \mathrm{kV}$ AC source. The electrical and optical measurements have also been reported. The use of solenoid as an external electrode has been found to be more effective in boosting the jet to a distance up to $30 \mathrm{~mm}$ even with a small flow rate of air. The characteristic of the proposed APPJ was investigated by measuring the effect of treatment on a PE film on the jet for different exposition time and distance from the nozzle. It has been confirmed that the jet can modify polymer film with a work distance of over $25 \mathrm{~mm}$. This plasma jet can be useful for the treatment and cleaning of objects having large structures and could be used in wider areas of application.
\end{abstract}

Keywords: APPJ, PE film, Air

\section{INTRODUCTION}

In the last one decade, the atmospheric pressure cold plasma research is highly increased due to its important applications in various fields. These types of plasma are non-equilibrium systems, where electron temperature is much higher than ion temperature. Atmospheric plasma cold plasma treatment of materials is a promising technology that is simpler to set-up, easier and economical to operate and does not require vacuum equipments.

Among the various applications of the atmospheric pressure cold plasmas, there are sterilizations of living tissue without damage and blood coagulation [1], modulation of cell attachment [2], biological and chemical decontamination [3-5], water decontaminations and pollution control [6-7], nanotechnologies [8], surface cleaning, etching, thin film deposition, surface modification and material processing [9-13].

In an atmospheric pressure plasma jet, plasma constituents are expelled through an orifice of a long nozzle along a gas flow. This type of plasma can be operated under high gas flow rate and can flow out plasma in space. In 2003, Toshifuji et al. reported a relatively cold arcplasma jet produced under atmospheric pressure having potential application for surface modification [14]. Quite recently, Takemura et al. developed an atmospheric pressure plasma jet with long flame. In this work it has been reported that the flame of $\mathrm{N}_{2}$ plasma jet has been elongated to about $200 \mathrm{~mm}$ length. It has been confirmed that the long flame plasma jet can modify polymer film with a work distance of over $200 \mathrm{~mm}$ [15]. Similarly, Choi et al. have recently reported a double layered atmospheric pressure which is expected to improve 
conventional single layered atmospheric pressure plasma jets [16]. In the same line, the objective of the present work is to develop the conventional APPJ and use of air to produce the plasma jet for polymer surface modification.

\section{EXPERIMENTAL DESCRIPTION}

Schematic diagram of the plasma jet is depicted in Fig. 1. A copper needle electrode of diameter $1 \mathrm{~mm}$ was placed inside a glass tube of inner diameter $4 \mathrm{~mm}$ and outer diameter 6 $\mathrm{mm}$. The outer electrode was an aluminum foil wrapped around the outer surface of the glass tube. The clearance around the central electrode was $1.5 \mathrm{~mm}$. The electrodes were connected to a high voltage $(0-20 \mathrm{kV})$ power supply operating at a frequency of $10-30 \mathrm{kHz}$. Air was passed through the inter-electrode space using an air pump. The temperature of the jet was measured by an IR thermometer. The gas temperature was in the range $26-28^{\circ} \mathrm{C}$ which shows that the plasma is non-thermal in nature. In order to evaluate the efficiency of the present APPJ, hydrophilicity test was performed. The contact angles are measured from the sessile drops of water made on the surface of PE films treated at different distances from the nozzle of the jet for different exposure times. Each contact angle presented in this paper is an average of at least 4 measurements made on different place of the film.

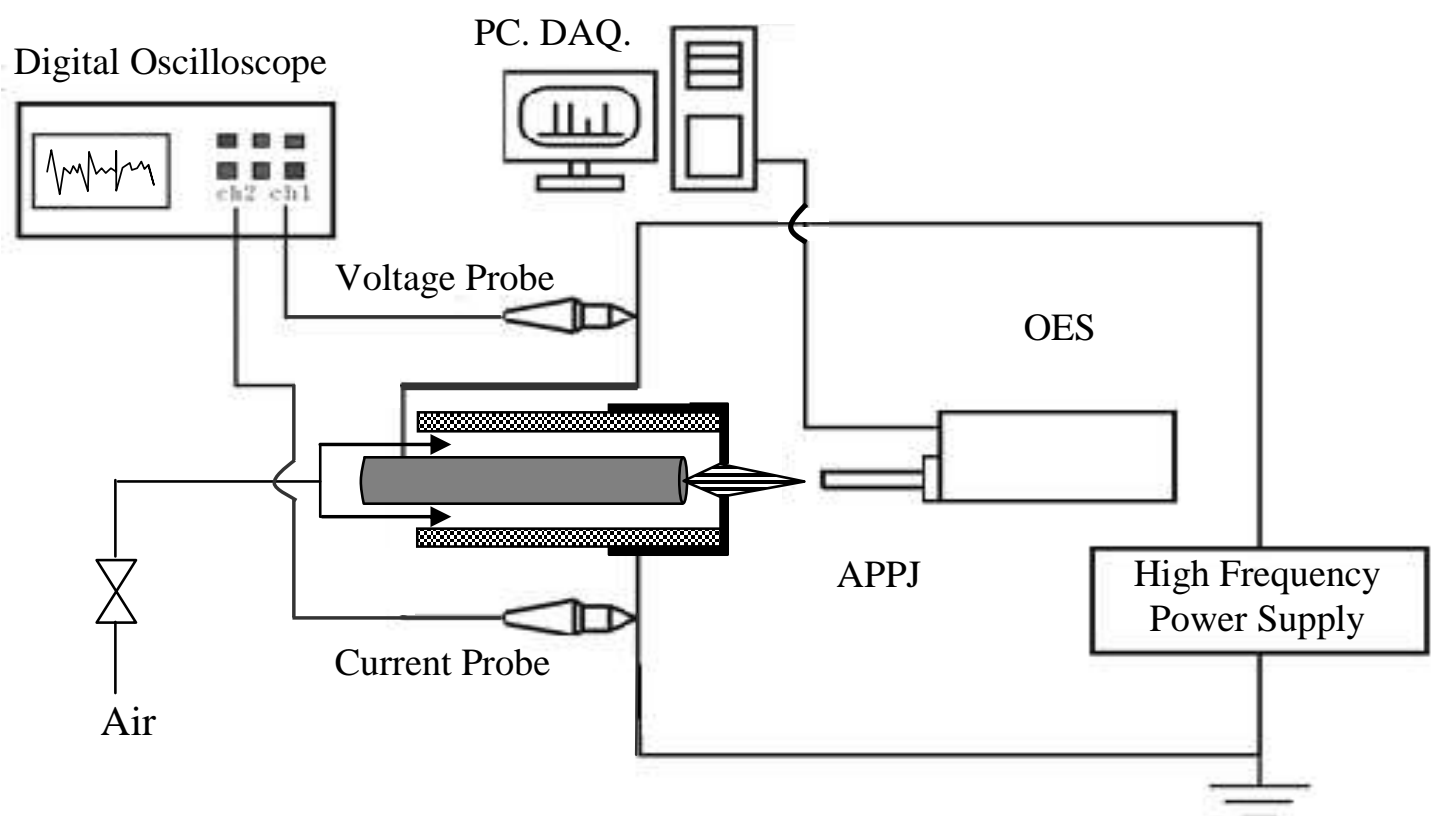

Fig.1 Experimental setup for arc plasma jet generation and characterization

Working gas is fed in to the annular space between two electrodes and air flows linearly at $30 \mathrm{~L} / \mathrm{min}$. After passing air in the inner volume of the reactor, plasma jet is spread out the nozzle with long frame. The input power has been maintain constant. The treatment is carried out by exposing the samples in the plasma jet flame with the help of rotating belt attached in the electric motor having 20rpm as shown in Fig. 2. 

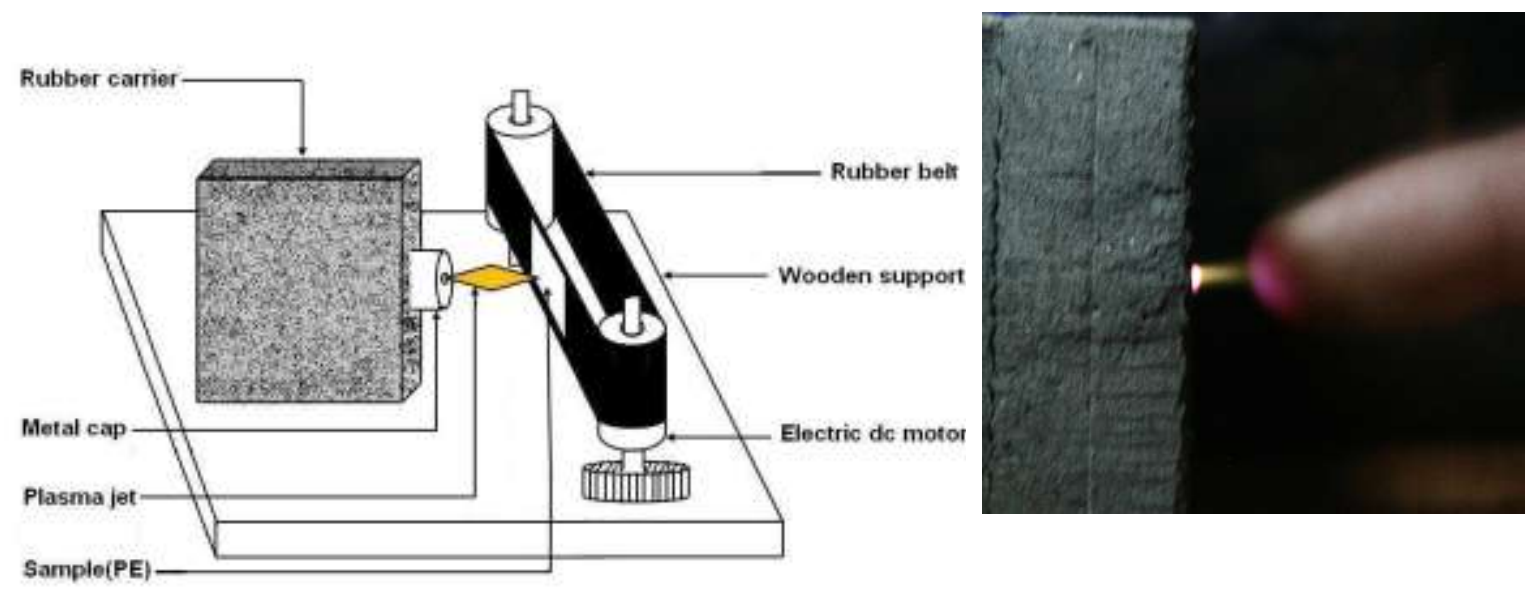

Fig. 2 Schematic diagram of PE treatment and showing the low temperature nature of the plasma jet being exposed to finger.

\section{CONTACT ANGLE ANALYSIS}

The most common method of quantifying wetting is the contact angle measurement. Furthermore, the measurement of contact angle on a solid surface is the most practical way to obtain information about surface energy: solid-vapor and solid-liquid surface tension. The contact angle $\theta$ is defined as the angle between the solid surface and the tangent to the surface of the drop at the point of contact of the two as shown in Fig. 3.

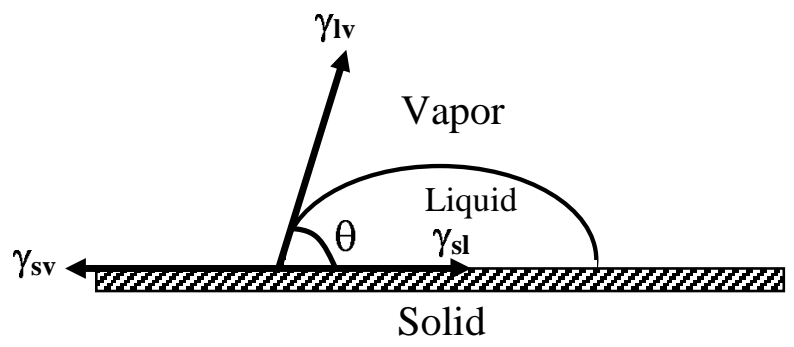

Fig. 3 Schematic diagram of the contact angle and interfacial tensions of the three surfaces at the three-phase boundary

The contact angle of a liquid drop on a solid substrate is related to interfacial tensions, which is given by Young's equation as.

$$
\gamma_{l v} \cos \theta=\gamma_{s v}-\gamma_{s l}
$$

where, $\gamma_{s v}$ is the surface free energy of the solid substrate, $\gamma_{s l}$ is the interfacial tension between the solid and the liquid and $\gamma_{1 v}$ is the surface tension of the liquid.

This equation shows that a perfect wetting i.e. $\cos \theta$ tending to unity is favored by a high energy surface solid, low interfacial free energy and low liquid surface free energy. 
The contact angle of a liquid on solid is strongly influenced by a number of factors such as surface roughness, chemical heterogeneity, sorption layers, molecular orientation and swelling. These effects have to be considered when contact angle measurements are used to calculate the solid surface tension.

In this study the contact angle of drops with the surface of the flat plate of PE was measured using a rame'- hart Contact Angle Goniometer model 200. This unit is equipped with standard software to analyze the drop image for the calculation of surface energy. The system offers a high level of computer aided precision in measuring contact angle and therewith facilitating the calculation of surface energy using different model equation.

\section{RESULTS AND DISCUSSION Effect of treatment time}

The change in wettability of PE surface after 1-10s treatment times in APPJ in air was quantitatively investigated by measuring contact angles with water. The graphical representation between treatment time verses contact angle and images of water drop on the surface of untreated and plasma treated PE surface and are depicted in Fig. 4. The water contact angle on PE after treatment in APPJ at power $12 \mathrm{~W}$ is plotted as a function of treatment-time in Fig. 4. The contact angle decreased rapidly from the original value of $104^{\circ}$ to about $44^{\circ}$ already after 5 s of treatment.

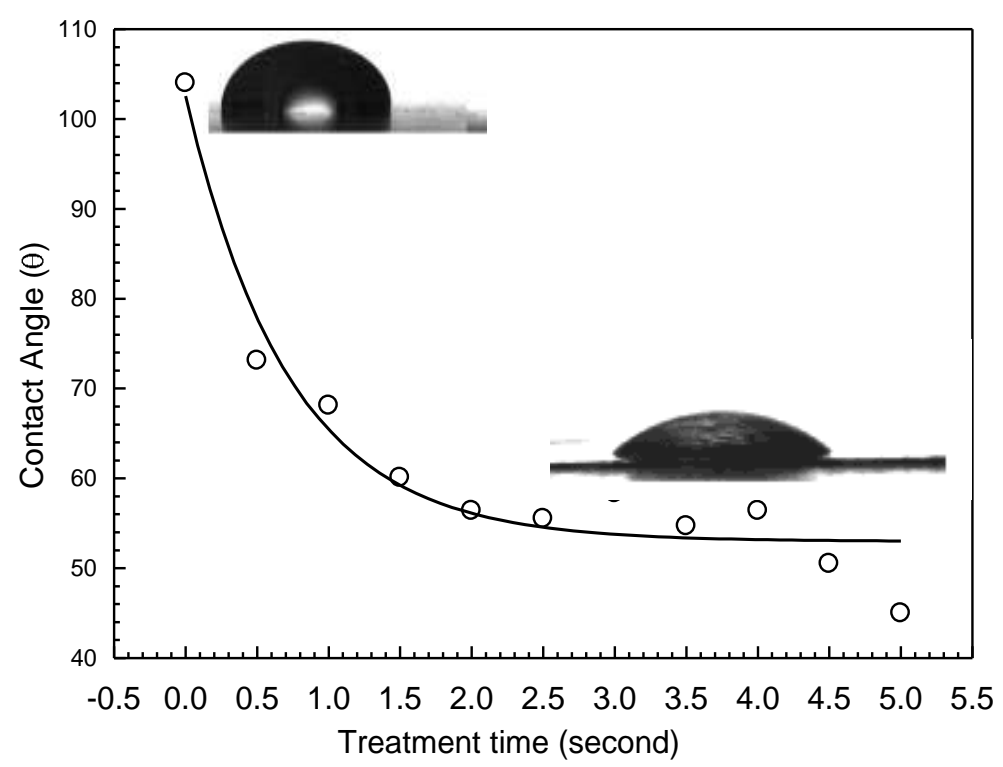

Fig. 4 Contact angle of water drop on PE film as a function of treatment time for RAPP. The distance from the nozzle was $5 \mathrm{~mm}$.

\section{Effect of distance}

The effect of distance of the nozzle of APPJ in PE treatment was clearly represented by the Fig. 5. When the constant treatment time 10s was fixed, contact angle was increased rapidly from 20mm distance to PE substrate and increase in contact angle was saturated from the distance $30 \mathrm{~mm}$ to PE substrate. This result shows that for the surface treatment of PE substrate suitable distance is less than $15 \mathrm{~mm}$ form nozzle of APPJ to substrate. 


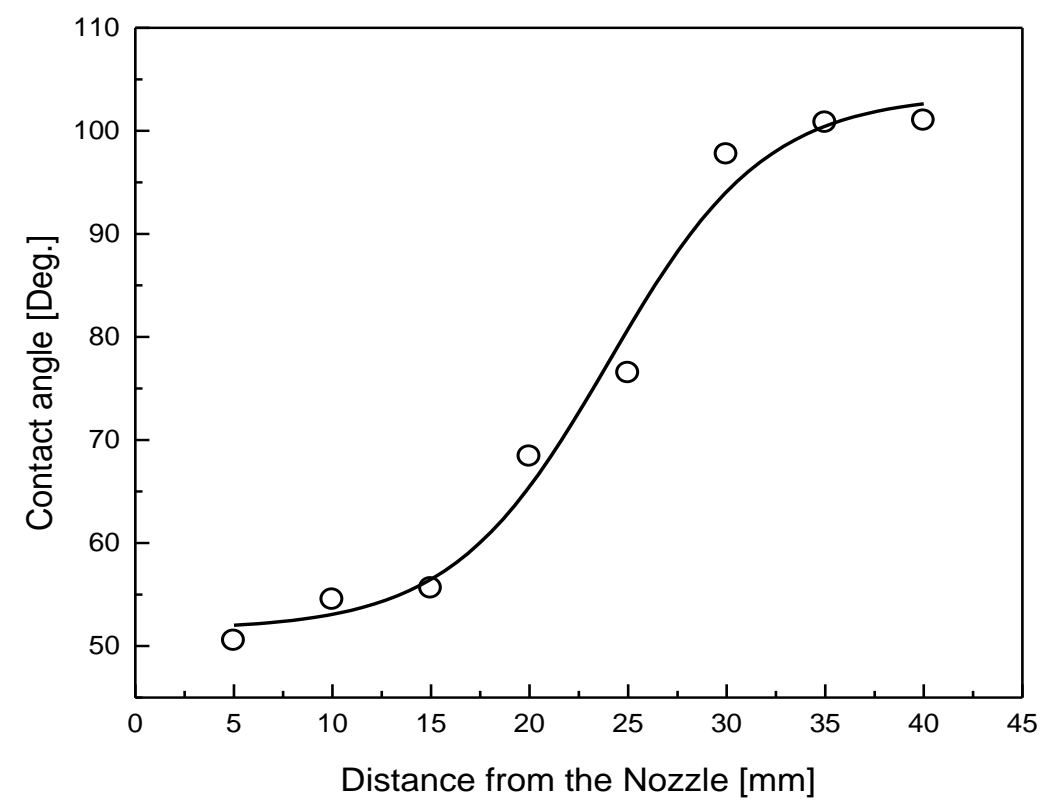

Fig. 5 Contact angle of water drop on PE film as a function of distance of the nozzle of RAPP in air. The treatment time was 10s.

\section{Current and voltage measurement}

Fig. 6 shows the typical oscillographic waveform of the discharge current and voltage with corresponding image of that discharge. This waveform gives measurement of current $(I)$ and voltage $(V)$ in the present of steamers in APPJ. And, apparent power was calculated from multiplying voltage by current. In the traced waveform, we have seen current is more fluctuated than voltage with respect to time. And, current leads the voltage. That is why; in our high voltage power supply capacitive load of APPJ is more than inductive load in side the power supply.

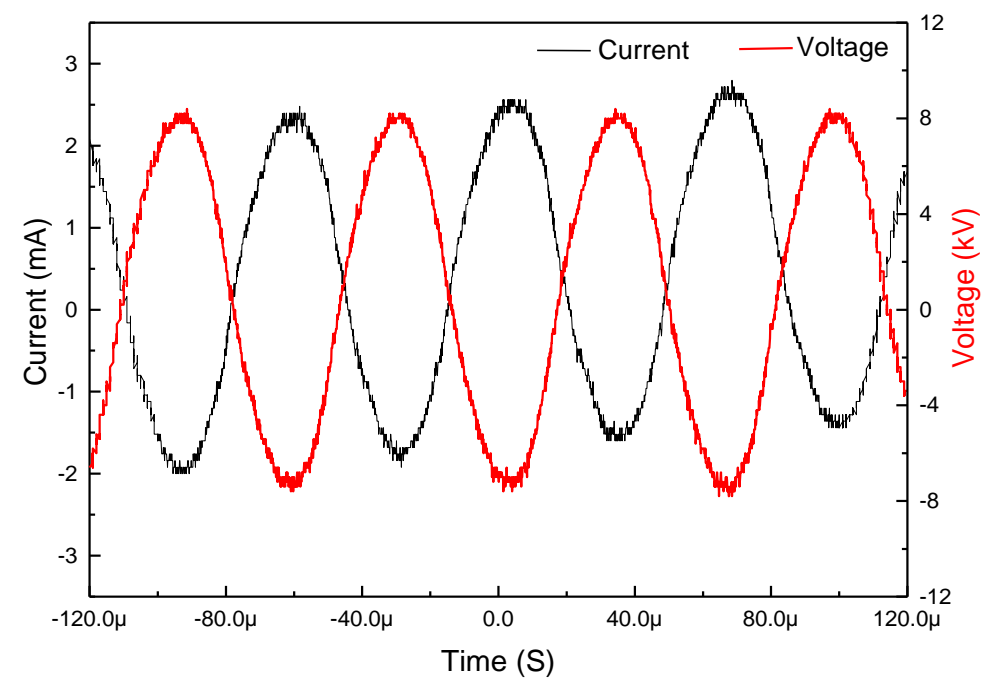

Fig. 6 Electrical measurements of APPJ 


\section{Optical spectrum analyses}

Fig. 7 shows optical emission spectra (OES) measured from the plasma jet produced in air. A Yovin Yvon optical emission spectrometer was used for the purpose. As seen from the graph the OES was dominated by the second positive system (SPS) of $\mathrm{N}_{2}\left(C^{3} \prod_{\mathrm{u}}-B^{3} \prod_{\mathrm{g}}\right)$. The first negative system (FNS) of $\mathrm{N}_{+2}\left(B^{2} \Sigma_{+\mathrm{u}}-X^{2} \Sigma_{+\mathrm{g}}\right)$ was also visible in violet range. No spectra from water vapor, oxygen and nitrogen oxide are observed within the wavelength range (200$800 \mathrm{~nm}$ ) due to sensitivity limitation of the monochrometer. Table 1 show that the significant spectral lines and the corresponding identified transition. The identified transitions were calculated based upon vibrational constants [17]

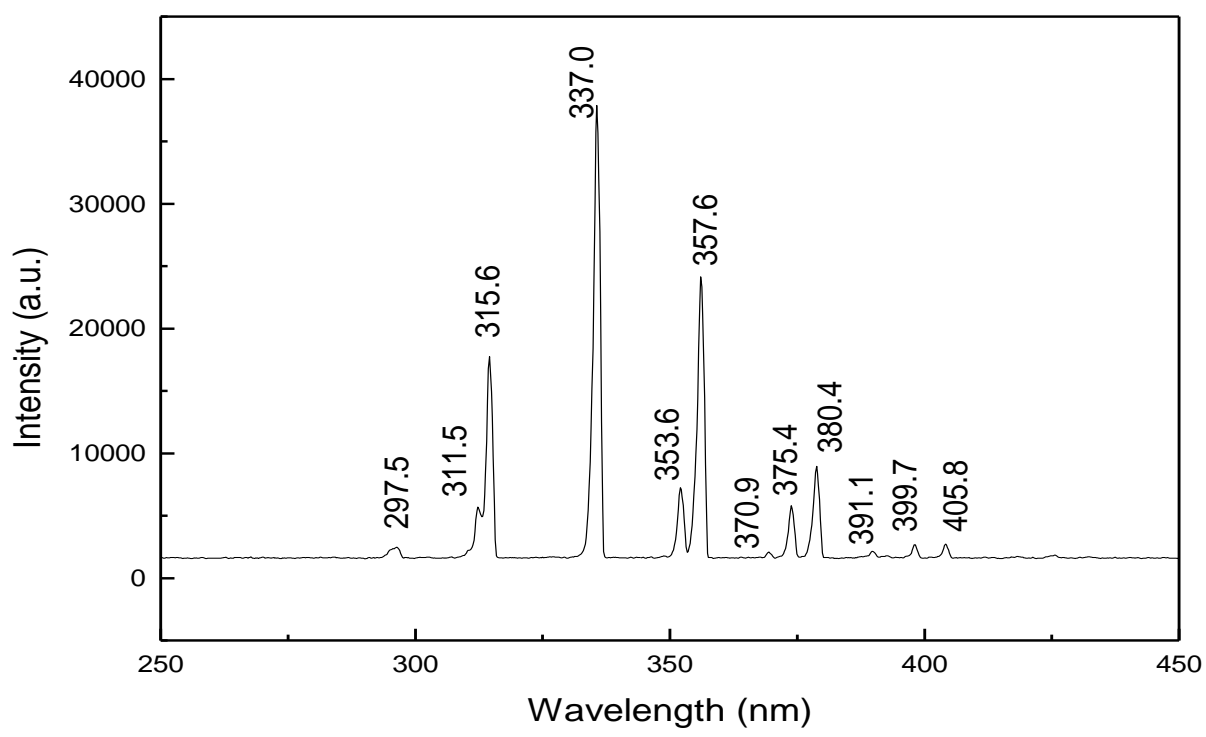

Fig. 7 Optical emission spectra of APPJ in the wavelength range of $250-450 \mathrm{~nm}$ where the observation position was $10 \mathrm{~mm}$ from the nozzle.

Table 1. Significant spectral lines in atmospheric pressure air discharge.

\begin{tabular}{|l|c|l|c|l|}
\hline $\begin{array}{l}\text { Excited } \\
\text { species }\end{array}$ & $\begin{array}{c}\text { Wavelength } \\
(\mathrm{nm})\end{array}$ & Electronic transition & $\begin{array}{c}\text { Vibrational } \\
\text { transition }\end{array}$ & $\begin{array}{l}\text { Peak } \\
(\%)\end{array}$ \\
\hline $\mathrm{N}_{2}$ & 297.5 & $\mathrm{~N}_{2}\left(\mathrm{C}^{3} \prod_{\mathrm{u}}-\mathrm{B}^{3} \prod_{\mathrm{g}}\right)$ & $2-0$ & 6.7 \\
\hline $\mathrm{N}_{2}$ & 311.5 & $\mathrm{~N}_{2}\left(\mathrm{C}^{3} \prod_{\mathrm{u}}-\mathrm{B}^{3} \prod_{\mathrm{g}}\right)$ & $3-2$ & 15.4 \\
\hline $\mathrm{N}_{2}$ & 315.6 & $\mathrm{~N}_{2}\left(\mathrm{C}^{3} \prod_{\mathrm{u}}-\mathrm{B}^{3} \prod_{\mathrm{g}}\right)$ & $1-0$ & 45.5 \\
\hline $\mathrm{N}_{2}$ & 337.0 & $\mathrm{~N}_{2}\left(\mathrm{C}^{3} \prod_{\mathrm{u}}-\mathrm{B}^{3} \prod_{\mathrm{g}}\right)$ & $0-0$ & 100 \\
\hline $\mathrm{N}_{2}$ & 353.6 & $\mathrm{~N}_{2}\left(\mathrm{C}^{3} \prod_{\mathrm{u}}-\mathrm{B}^{3} \prod_{\mathrm{g}}\right)$ & $1-2$ & 19.3 \\
\hline $\mathrm{N}_{2}$ & 357.6 & $\mathrm{~N}_{2}\left(\mathrm{C}^{3} \prod_{\mathrm{u}}-\mathrm{B}^{3} \prod_{\mathrm{g}}\right)$ & $0-1$ & 53.9 \\
\hline $\mathrm{N}_{2}$ & 370.9 & $\mathrm{~N}_{2}\left(\mathrm{C}^{3} \prod_{\mathrm{u}}-\mathrm{B}^{3} \prod_{\mathrm{g}}\right)$ & $2-4$ & 5.5 \\
\hline $\mathrm{N}_{2}$ & 375.4 & $\mathrm{~N}_{2}\left(\mathrm{C}^{3} \prod_{\mathrm{u}}-\mathrm{B}^{3} \prod_{\mathrm{g}}\right)$ & $1-3$ & 15.6 \\
\hline $\mathrm{N}_{2}$ & 380.4 & $\mathrm{~N}_{2}\left(\mathrm{C}^{3} \prod_{\mathrm{u}}-\mathrm{B}^{3} \prod_{\mathrm{g}}\right)$ & $0-2$ & 23.6 \\
\hline $\mathrm{N}_{+2}$ & 391.1 & $\mathrm{~N}_{+2}\left(\mathrm{~B}^{2} \sum_{+\mathrm{u}}-\mathrm{X}^{2} \Sigma_{+\mathrm{g}}\right)$ & $0-0$ & 5.6 \\
\hline $\mathrm{N}_{2}$ & 399.7 & $\mathrm{~N}_{2}\left(\mathrm{C}^{3} \prod_{\mathrm{u}}-\mathrm{B}^{3} \prod_{\mathrm{g}}\right)$ & $1-4$ & 6.7 \\
\hline $\mathrm{N}_{2}$ & 405.8 & $\mathrm{~N}_{2}\left(\mathrm{C}^{3} \prod_{\mathrm{u}}-\mathrm{B}^{3} \prod_{\mathrm{g}}\right)$ & $0-3$ & 7.1 \\
\hline
\end{tabular}




\section{CONCLUSION}

An atmospheric pressure plasma jet in air has been developed for PE surface modification. APPJ to improve the wettability of PE film has been tested successfully in this laboratory. It was found that the hydrophilicity of the PE film surface is linearly dependant on distance effect, while the effective exposure time can be as brief as 4 second. The characteristics of electrical and optical properties in our studies are similar to low temperature plasma.

\section{ACKNOWLEDGEMENTS}

The authors would like to thank Prof. C. S. Wong, Department of Physics, University of Malaya, Kuala Lumpur, Malaysia, for his valuable suggestions during our work. We are also thankful to Dr. Peter Ferer for his help in fabricating the power supply.

\section{REFERENCES}

[1] Fridman G, "Blood coagulation and living tissue sterilization by floating electrode dielectric barrier discharge in air", Plasma chem. and plasma process., 26 (2006) 425-442,.

[2] Stoffels E, Kieft I \& Sladek R, "Superficial treatment of mammalian cells using plasma needle", J. Phys. D. Appl. Phys., 36 (2003) 2908-2913,

[3] Laroussi M, "Low temperature plasma based sterilization: Overview and state of the art”, Plasma Process. Polym., 2 (2005) 391-400,

[4] Walsh J L \& Kong M G, "Contrasting characteristics of linear-field and cross-field atmospheric plasma jets”, Appl. Phys. Lett., 93 (2008) 111501

[5] Lu X, Ye T, Y Cao, S Sun, Xiong Q, Tang Z, Xiong Z, Hu J, Jiang Z \& Pan Y, 'The role of the various plasma agents in the inactivation of bacteria", J. Appl. Phys.,104 (2008) 053309

[6] Bruggeman P \& Leys C, "Non thermal plasmas in and in contact with liquids", $J$. Phys. D: Appl. Phys., 42 (2009) 053001

[7] Kolb J F, Joshi R P, Xiao S \& Schoenbach K H, "Stremears in water and other dielectric liquids", J. Phys. D. Appl. Phys., 41 (2008) 234007

[8] Gonzales-Aguilar J, Moreno M \& Fulcheri L, "Carbon nanostructures production by gas-phase plasma processes at atmospheric pressure", J. Phys. D: Appl .Phys., 40 (2007) 2361-2374

[9] Schutze A, Jeong J Y, Banayan S E, Park J, Selwyn G S \& Hicks R F, " The atmospheric pressure plasma Jet: A review and comparison to other plasma sources", IEEE Trans. Plasma Sci., 26 (1998)1685-1694 
[10] Kunhardt E E, "Generation of large volume, atmospheric-pressure non equilibrium plasmas”, IEEE Trans. Plasma Sci., 28 (2000)189-200

[11] Daun Y, Hung C \& Yu Q S "Low temperature direct current golw discharges at atmospheric pressure”, IEEE Trans. Plasma Sci., 33 (2005) 328-329

[12] Borcia G, Chiper A \& Rusu I, "Using a He $+\mathrm{N}_{2}$ dielectric barrier discharge for the modification of polymer surface properties", Plasma sources Sci. Technol.,15 (2006) 849-857

[13] Benedict J, Forcke K, Yanguas-Gil A \& Von Keudell A, “Atmospheric pressure micro plasma jet as a depositing tool”, J. Appl. Phys. 99 (2006) 112303

[14] Tioshifuji J, Katsumata T, Takikawa H, Sakakibara T \& Shimizu I, "Cold arc- plasma jet on the atmospheric pressure for surface modification", Surface and Coating Tech., 171 (2003) 302-306

[15] Takemura Y, Kubota Y, Yamaguchi N \& Hara T, "Development of atmospeheric plasma jet with long flame”, IEEE Trans. Plasma Sci., 26 (2009)1604-1606

[16] Choi J, Matsuo K, Yoshida H, Namihira T, Katsuki S \& Akiyama H, "Double layer atmospheric plasma jet”, Japanese J. of Appl. Phys., 48 (2009) 086003

[17] Laher R R \& Gilmore F R, J. Phys. Chem. Ref. Data, 20 (1991) 685 